\title{
Littoral Pycnogonida from Oman
}

\author{
Jan H. Stock \\ Institute of Taxonomic Zoology, University of Amsterdam, P.O. Box 4766, 1009 AT Amsterdam, \\ The Netherlands
}

Keywords: Pycnogonida, littoral, Oman, taxonomy

\begin{abstract}
Sixteen species of Pycnogonida are recorded from littoral or very shallow waters $(0-3 \mathrm{~m})$ of the coast of Oman. Four species are new to science: Ammothella omanensis, Achelia boschi, A. lagenaria, and Pycnogonum moolenbeeki. Since up to now no littoral Pycnogonida have been recorded from the Arabian peninsula, all other species are new to this region, with the exception of one which was recorded from deeper waters off Oman before. For some of them the range is considerably extended.
\end{abstract}

\section{Résumé}

Seize espèces de Pycnogonides sont signalées du littoral ou bien des eaux fort peu profondes $(0-3 \mathrm{~m})$ des côtes d'Oman. Quatre espèces sont nouvelles pour la science: Ammothella omanensis, Achelia boschi, A. lagenaria, et Pycnogonum moolenbeeki. Jusqu'à présent aucun Pycnogonide littoral n'ayant été signalé pour la Péninsule Arabique, les autres espèces sont nouvelles pour cette région, l'exception étant une espèce déjà signalée d'eaux plus profondes au large d'Oman. L'aréal connu de certaines espèces se trouve considérablement élargi.

\section{Introduction}

A small number of papers have been published on the medio- and infralittoral pycnogonids from the northwestern and western Indian Ocean: Gulf of Suez and Gulf of Aqaba (Stock, 1957, 1958), Ethiopia (Stock, 1964), Somalia (Stock, 1982), Kenya (Arnaud, 1973; Müller, 1990a, b), and Tanzania (Stock, 1975a). However, no littoral Pycnogonida have ever been recorded from the Arabian peninsu- la. So, a sizable collection (198 specimens, belonging to 16 species from 14 different stations), handcollected by Mr. R.G. Moolenbeek and Mr. H. Dekker in November 1991 on the coast of Oman, form an important contribution to the knowledge of the pycnogonid fauna of the Indian Ocean.

The following taxa are represented:

Family Ammotheidae Dohrn, 1881

Genus Ascorhynchus Sars, 1877

$A$. corderoi Du Bois-Reymond Marcus, 1952

Genus Nymphopsis Haswell, 1884

$N$. bathursti Williams, 1940 [new rank]

Genus Ammothella Verrill, 1990

A. appendiculata (Dohrn, 1881)

$A$. omanensis n. sp.

Genus Achelia Hodge, 1864
$A$. boschi n. sp.
A. lagenaria n. sp.
A. watumu (Müller, 1990a)

Genus Tanystylum Miers, 1879

T. bredini Child, 1970

Family Callipallenidae Hilton, 1942

Genus Pigrogromitus Calman, 1927

$P$. timsanus Calman, 1927

Genus Propallene Schimkewitsch, 1909

$P$. crassimanus Stock, 1959

Genus Callipallene Flynn, 1929

C. gabriellae Corrêa, 1948 [ = C.

kenyensis Müller, 1990a, new

synonymy]

Family Phoxichilidiidae Sars, 1891 
Genus Anoplodactylus Wilson, 1878

$A$. angulatus (Dohrn, 1881)

A. digitatus (Böhm, 1879)

A. glandulifer Stock, 1954

A. tarsalis Stock, 1968

Family Pycnogonidae Wilson, 1878

Genus Pycnogonum Brünnich, 1764

$P$. moolenbeeki n. sp.

All specimens, including the types of the new species, have been deposited in the Zoölogisch Museum, Amsterdam (ZMA).

\section{List of stations}

The material examined was collected at the following stations on the Oman coast:

Sta. 91/50: Al Bustan, $2 \mathrm{mi}$. (= $3.2 \mathrm{~km})$ E. of Muscat, near Aquarium, low tide, under stones $9 \& 16$ Nov. 1991.

Sta. 91/58: prov. Dhofar, Raysut near Salalah, Beercan beach, 1-4 m, from algae and bottom material, 11 Nov. 1991.

Sta. 91/61: Kuria Muria Islands, Al Hallaniyah, main island, form intertidal stones, 12 Nov. 1991.

Sta. 91/65: prov. Dhofar, Wadi Kharfot, $10 \mathrm{~km} \mathrm{W.} \mathrm{of} \mathrm{Rah-}$ kyut, intertidal, under rocks and stones, 13 Nov. 1991.

Sta. 91/74: prov. Dhofar, Ra's Janjali $\left(17^{\circ} \mathrm{N} 55^{\circ} \mathrm{E}\right)$, on algae, 0-3 m, 14 Nov. 1991.

Sta. 91/79: prov. Dhofar, Khor Rouri, bay, on algae, 15 Nov. 1991.

Sta. 91/83: Haramal near Muscat, 17, 24 \& 28 Nov. 1991.

Sta. 91/93: Masirah Island, Valley of the Moon beach, tidal pools, on stones, 20 Nov. 1991.

Sta. 91/94: Masirah Island, Maghilah, from stones in tidal pools, 20 Nov. 1991.

Sta. 91/99: Masirah Island, Umm Rasas (Rusays), halfway east coast, muddy tidal flat with stones and algae, 21 Nov. 1991.

Sta. 91/105: Masirah Island, Ra's al Ya, low tide, under stones and on beach, 23 Nov. 1991.

Sta. 91/111: Masirah Island, $0.5 \mathrm{~km} \mathrm{E}$. of Ra's abu Rasas, low tide, stones and algae, 24 Nov. 1991.

Sta. 91/117: Haramal near Muscat, intertidal, 28 Nov. 1991.

Sta. 91/120: Al Bustan, near Aquarium, from coralline algae, 0.5-1 m, 29 Nov. 1991.

\section{Taxonomic part}

Ascorhynchus corderoi Du Bois-Reymond Marcus, 1952

Ascorhynchus corderoi Du Bois-Reymond Marcus, 1952: 23-30, figs. 1-9; Stock, 1953: 304 (in key); Weidner, 1959: 106 (type list); Stock, 1965: 14; Child, 1988b: 52.

Material. - Sta. 91/83, 1 hermaphrodite.

Remarks. - The present specimen, like several specimens recorded before, has internal ova in the coxae and femur, and one egg ball on the ovigers (a male character). Mrs. Marcus (1952) showed this species to be hermaphrodite.

Although originally described from southern Brazil, later records are from the Indian Ocean (Mauritius, Aldabra atoll). The range is now extended to Oman.

Nymphopsis bathursti Williams, 1940 [new rank] (Fig. 1)

Nymphopsis acinacispinatus var. bathursti Williams, 1940: 200-201, figs. 4-5.

N. acinacispinatus bathursti; Clark, 1963: 5 (check-list); Child, 1975: 26-27, figs. $11 \mathrm{c}-\mathrm{f}$.

Material. - Sta. 91/74, 1 ९; sta. 91/79, $1 \sigma^{\circ, 2}$,, 1 juv.; sta. 91/94, 1 \&; sta. 91/99, 2 ○ \%, 2 ९ \&.

Remarks. - According to the International Code of Zoological Nomenclature (ICZN, 1985), art. 30 (a), the gender of genus-group names ending in -opsis are feminine. Accordingly, the original spelling of the species name acinacispinatus should be corrected into acinacispinata.

Although the two infraspecific taxa attributed to Nymphopsis acinacispinata (viz. N. a. acinacispinata Williams, 1933 and $N$. a. bathursti Williams, 1940) are phenetically closely related, I do consider them for the moment distinct species, not as varieties or subspecies. My reasons for doing so are both biogeographical and morphological:

(1) The distributions of both alleged subspecies largely overlap. $N$. a. acinacispinata is known from Queensland (Port Curtis, 5-8 fms = c. 9-15 m; Williams, 1933) and the Travancore coast, India (Vizhingom Bay, 6-8 fms = c. 11-15 m; Kurian, 1953). N. a. bathursti has been collected in Western Australia (Rotnest Island, W. of Rockingham, Cockburn Sound, Cottesloe, and Perth, 0-1 m; Child, 1975) and presently from Oman (intertidal).

(2) There are three points in the morphology of 


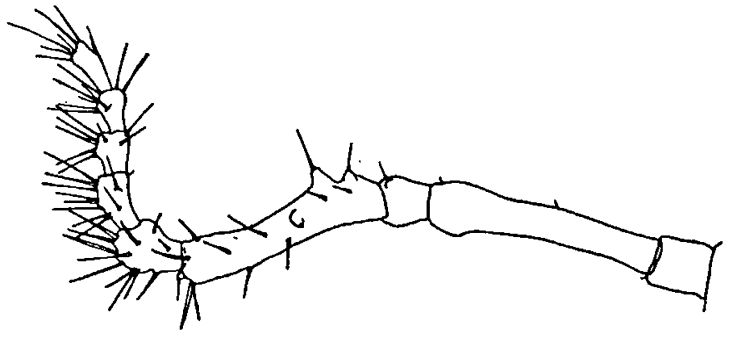

Fig. 1. Nymphopsis bathursti Williams, 1940: palp, ${ }^{\circ}$, from sta. 91/99.

the single described specimen of $N$. a. acinacispinata that prevent synonymization with bathursti as Child prudently suggests. These three points are the armature of the first tibia (strong spiniferous processes limited to the proximal half of the segment in acinacispinata, all over the segment in bathursti); the presence of a long male genital spur on coxa 2 of legs 2 to 4 in acinacispinata, on legs 3 and 4 in bathursti; and the length of the auxiliary claws $(50 \%$ of the main claw in acinacispinata, distinctly less than $50 \%$ in bathursti).

The palp of $N$. bathursti was never figured in great detail. In our Fig. 1 this appendage is shown; note that the two spiniferous tubercles on palp segment 4 are situated far more proximally than Williams' Fig. 4 suggests.

The present records extend the range of $N$. bathursti to the Oman coast, on the other side of the Indian Ocean.

\section{Ammothella appendiculata (Dohrn, 1881)}

Ammothella appendiculata; Child, 1992: 12 (refs.).

Material. - Sta. 91/50, 1 \%; sta. 91/79, 1 o ovig.; sta. 91/93, $1 \sigma^{\circ}$ ovig., 2 juvs.

Remarks. - This species has frequently been recorded from the warm-water region of the western and eastern Atlantic and the Mediterranean. There is one record from the eastern Pacific (Panamá; Child, 1979) and a few records exist from the Red Sea area (Suez, Eilat, Dahlak Archipelago; Stock, 1957, 1958, 1964).

The legs of the Oman specimens are slightly more slender than in amphi-Atlantic material, but otherwise they appear to be very similar.
Ammothella omanensis n. sp.

(Figs. 2-3)

Material. - Sta. 91/74, 1 o ovig. (holotype, ZMA Pa. 3555); sta. 91/79, $1 \sigma^{\circ}, 1$ ○ (paratypes, ZMA Pa. 3560); sta. 91/79, 2

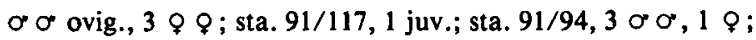
sta. $91 / 120,1 \sigma^{\circ}$.

Description of male (holotype). - Trunk (Fig. 2a) completely segmented. Anterior margin of cephalic segment with strong spine on either corner. Lateral processes shorter than diameter of trunk, wellseparated, dorsodistally with 3 spines and 1 tubular spine (which is sometimes absent or broken off). Ocular tubercle (Fig. 2b) slightly inclining forward, tall, essentially cylindrical; apex produced into rounded point above small, pigmented eyes. Abdomen forming strong arch (convexity on dorsal side); tip overreaching coxa 1 of leg 4. Proboscis (Fig. 2c) bulbous and massive, with very slight subdistal constriction.

Chelifore (Fig. 2d) scape long (chela overreaching tip of proboscis), 2-segmented; segment 1, although long, shorter than segment 2. Scape without processes but with several tubular spines; these spines, like those occurring on the legs, bear some minute marginal denticles, visible only at strong magnification. Chela reduced to conical stump; movable finger present as cylindrical rudiment. Scape segments as well as chela separated by wide intersegmental membranous zones.

Palp (Fig. 3c) 9-segmented. Wide intersegmental membranes between segments 3 and 4, and 5 and 6 . Segment 4 longest. Segment $6>$ segment 5 , very slender. Segment 9 slender $>$ segment $7>$ segment 8.

Oviger (Fig. 3b) 10-segmented; segments 4 and 5 with longitudinal row of setae; segment 6 without recurved spine but with several setae; segment 7 with apico-ectal setose lobe; segment 8 implanted anaxially. Compound spine formula $2: 2: 1: 2$. Distal compound spines (Fig. 3d) large, lanceolate, with a dozen marginal teeth.

Legs with several tubular spines on coxae 1 and 3, femur and tibiae 1 and 2 (third leg, see Fig. 2f); furthermore numerous smooth setae on leg segments, those in distodorsal part of both tibiae longer than segment diameter. Cement gland tube rather long, 


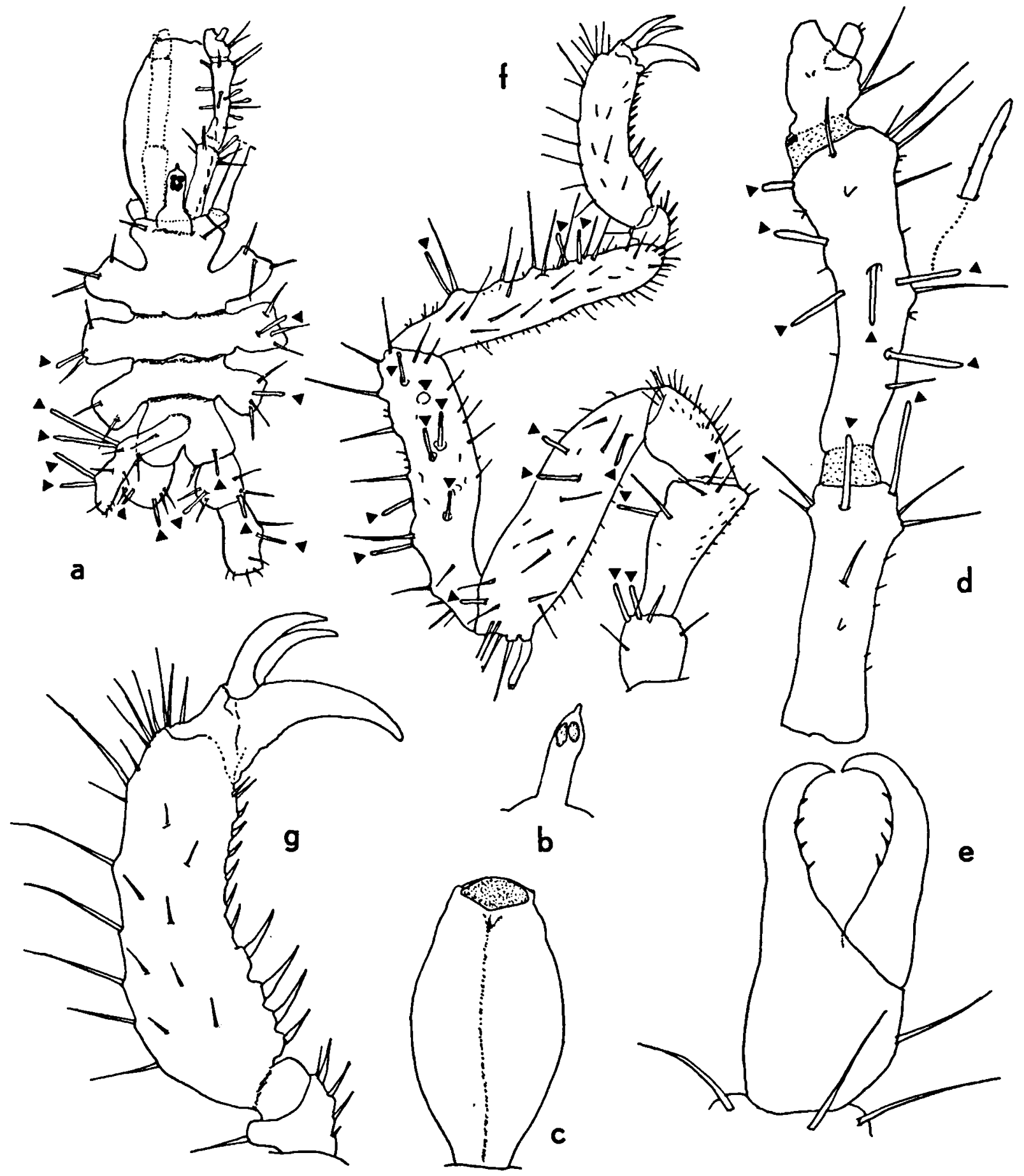

Fig. 2. Ammothella omanensis n. sp.; $\sigma$ from sta. 91/74; juvenile from sta. 91/117: a, trunk, $\sigma$, dorsal; b, ocular tubercle, $\sigma$, from the right; $c$, proboscis, $\sigma$, ventral; $d$, chelifore, $\sigma ; \mathrm{e}$, chela, juvenile; $f$, third leg, $\sigma ; \mathrm{g}$, distal segments of third leg, $\sigma$. [Triangles denote tubular spines.] 

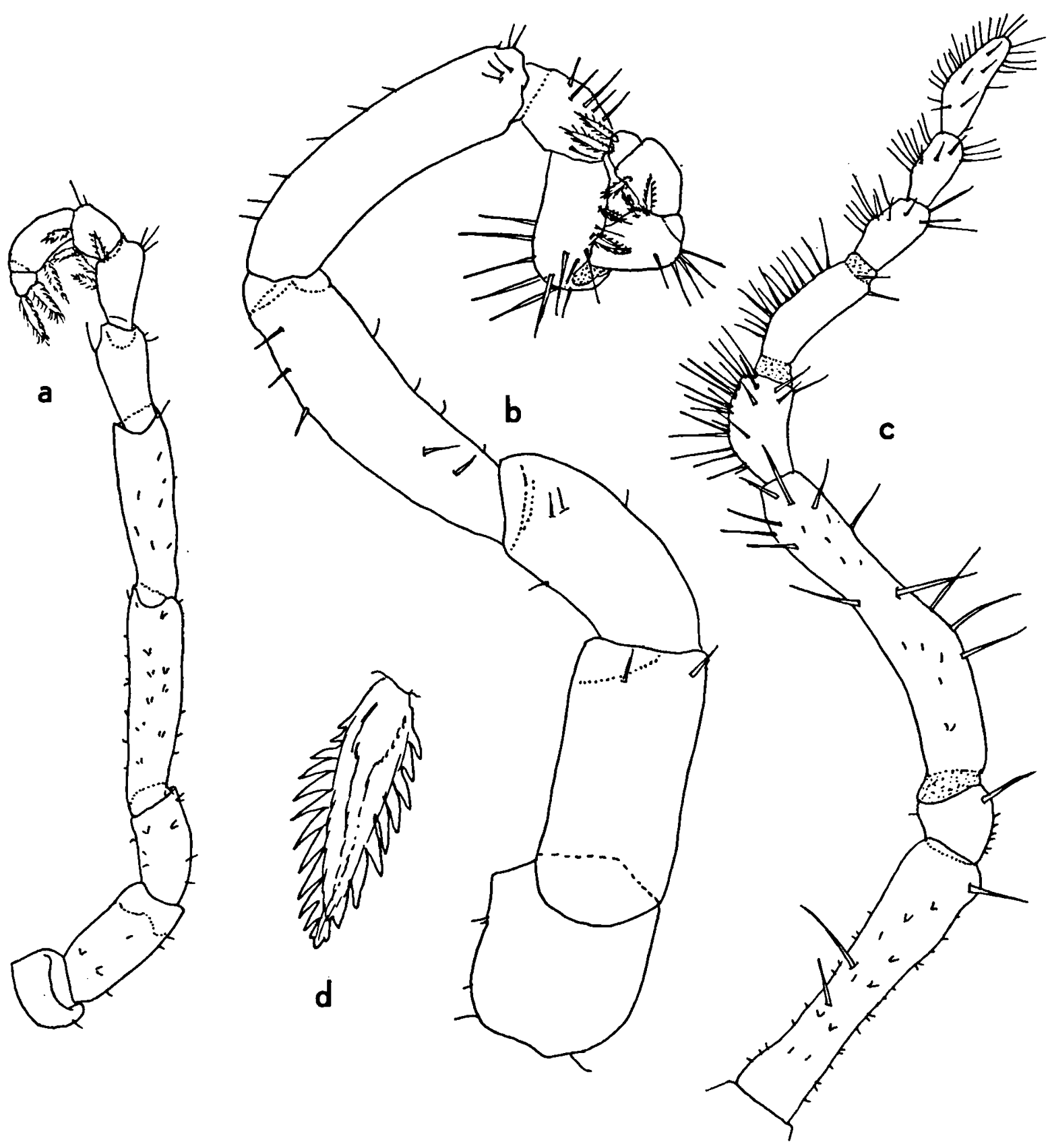

Fig. 3. Ammothella omanensis n. sp.; १ from sta. 91/79; $\sigma^{\circ}$ from sta. 91/74: a, oviger, $\$$; b, oviger, $\sigma^{\circ}$; c, palp, $\sigma^{\circ}$; d, distal compound spine of oviger segment $10, \sigma$.

dorsal, situated near distal end of femur. Propodus (Fig. 2g) curved; heel with 4 long heel spines; sole with $c$. 8 short spines. Claw curved, rather short; auxiliary claws more than half as long as claw.
Female. - Hardly less spinous than male. Abdomen looking slightly longer. Oviger (Fig. 3a) smaller than in male; segments 4,5 , and 6 with minute setules only; segment 7 with 3 compound 
spines; articulation between segments 7 and 8 slightly anaxial; fewer and shorter setae on segments 7 and 8.

Juvenile. - Less spinous than adults. Chelae (Fig. 2e) still perfectly chelate; fingers with some denticles.

Measurements of male holotype (mm). - Length trunk (anterior margin cephalon to tip 4th lateral process) 1.46; width across 2 nd lateral processes 1.07; length proboscis (dorsal) 0.91; greatest diameter proboscis 0.66 ; first scape segment 0.47 ; second scape segment 0.62 .

Third leg: first coxa 0.32; second coxa 0.54; third coxa 0.36; femur 0.98; first tibia 1.03; second tibia 0.99 ; tarsus 0.11 ; propodus 0.56 ; claw 0.29 ; auxiliary claws 0.19 .

Etymology. - Named after the Sultanate of Oman, where the species was found.

Remarks. - This new species is phenetically close to Ammothella schmitti Child, 1970 from the Society Islands. The differences with $A$. schmitti pertain to (1) the more slender legs of $A$. omanensis (in particular on the level of coxa 2, femur, and tibiae); (2) the presence of 2 spines on the anterior margin of the cephalic segment in $A$. omanensis (tubercles in A. schmitti); (3) more slender distal palp segments; (4) setae on legs and palps being smooth, not feathered; (5) anaxially articulated oviger segments 7 and 8 (synaxially in $A$. schmitti).

Differences from other look-alikes ( $A$. heterosetosa Hilton, 1942 and $A$. dawsoni Child \& Hedgpeth, 1971) are discussed by Child (1970: 295).

One of the specimens from sta. 91/94 shows a curious anomaly: the right chelifore scape is 3-segmented, instead of 2-segmented.

Achelia boschi n. sp.

(Figs. 4-5)

Material. - Sta. 91/79, $1 \sigma^{\circ}$ (holotype), $3 \sigma^{\circ} \sigma^{\circ}$ and $9 \%$ (paratypes) (ZMA Pa. 3547); sta. 91/65, 1 ९; sta. 91/99, $1 \sigma^{\circ}$.

Description of male. - Body (Fig. 4a) slightly longer than wide, compact, lateral processes touching. Frontal margin of cephalon with several spinule-tipped tubercles. Each lateral process with 2 to 4 spine-tipped, truncate tubercles. Trunk segments 1, 2, and 3 articulated; segment 4 fused with 3. Ocular tubercle (Fig. 4b) with tall, pointed tip above the narrow, well-pigmented eyes. Abdomen variable in length, but overreaching 4th lateral process, armed with spine-tipped tubercles and several spinules; directed upward at an angle of $c$. $30^{\circ}$. Proboscis spindle-shaped in outline, indistinctly tripartite.

Chelifores (Fig. 4c) less than half as long as proboscis; scape with 3 distal tubercles, each armed with strong distal spine. Chela reduced to globular structure bearing 1 spine and minute pointed process.

Palp (Fig. 4d) 8-segmented. Segments 5 to 8 short (not elongate); distal three segments somewhat bulgy or clavate in outline; segment 7 as long as wide.

Oviger (Fig. 4f) of usual structure. Segments 2 and 3 relatively short. Segments 4 and 5 with longitudinal row of reversed spines. Segment 6 with 3 reversed spines (1 strong). Compound spines (Fig. $4 \mathrm{~g}$ ) on segments 7 to 10 , according to formula 2:2:2:2; distal compound spines with 3 or 4 marginal serrations.

Legs (Figs. 5b, c) shortish in comparison with related species. Coxa 1 with 5 to 7 anterior, distal, and posterior spurs, all spiniferous. Coxa 2 with 2 anterior and 3 posterior truncate, spine-tipped tubercles. Genital spur on distoventral corner of coxa 2 of legs 3 and 4, finger-shaped, armed with small spinules. Coxa 3 with some low tubercles. Femur slightly swollen (in both sexes!), armed with several spiniferous tubercles and 1 spiniferous dorsodistal spur, through which discharges the cement gland. Femur $>$ tibiae 1 and 2 . Tibia 1 subequal to tibia 2, both tibiae with numerous dorsal and lateral, truncate, spine-tipped tubercles. Propodus (Fig. 5c) curved; 3 or 4 heel spines, 5 or 6 sole spines; claw strong, with 2 to 5 denticles on lateral surface of proximal part; auxiliary claws more than half as long as claw.

Female. - Leg 3 as illustrated (Fig. 5a); tubercles 


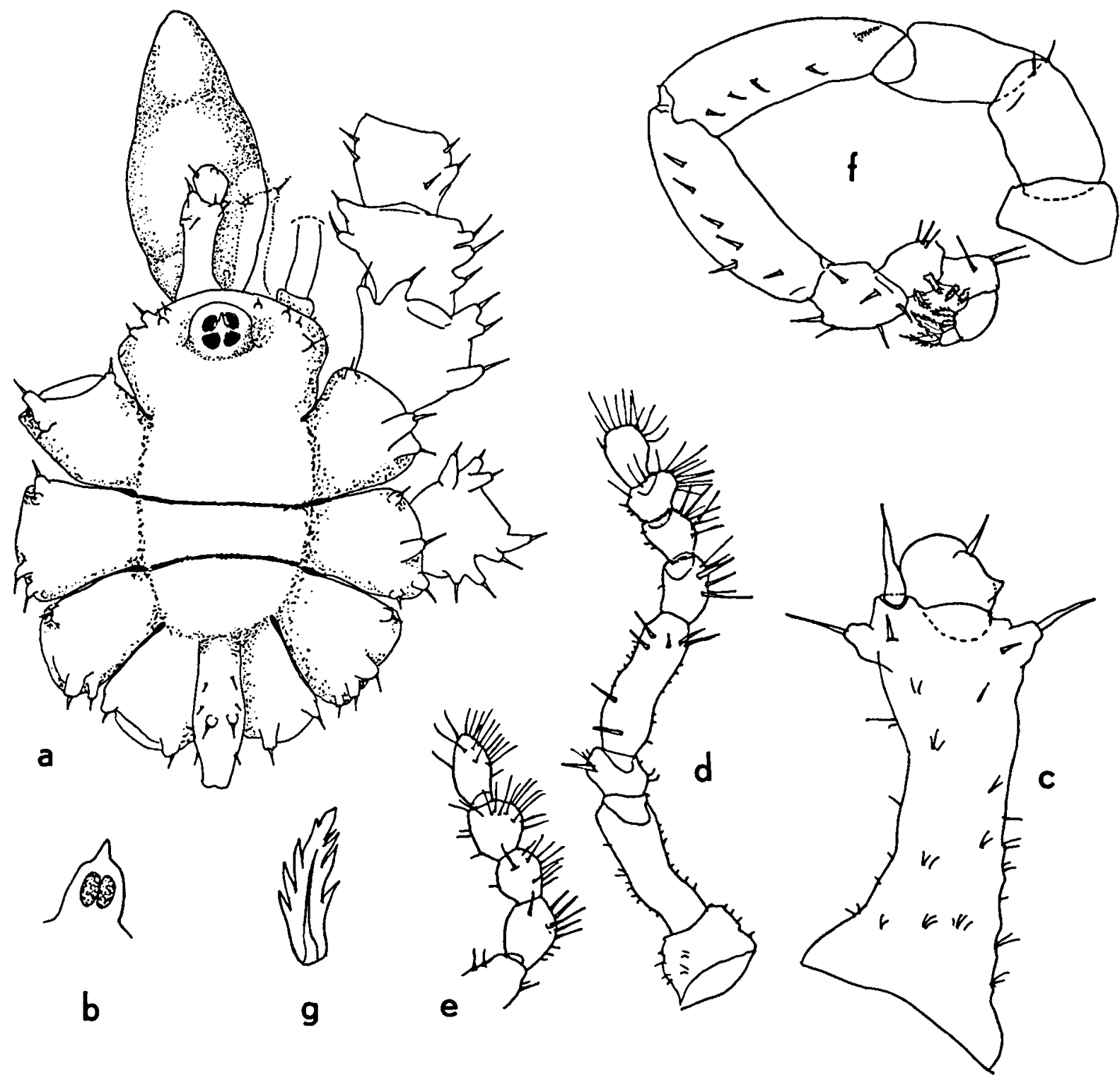

Fig. 4. Achelia boschi n. sp., from sta. 91/79: a, trunk, $\sigma$, dorsal; b, ocular tubercle, $\sigma \circ$, from the right; c, chelifore, $\sigma^{\circ}$; d, palp, $\sigma^{\circ}$; e, distal palp segments, $Q$; f, oviger, $\sigma ; \mathrm{g}$, terminal compound oviger spine, $\sigma$.

on lateral processes and coxae slightly lower than in male, but present. Coxa 2 shorter, provided with ventral sexual pore on all legs. Femur, and tibiae in particular, as strongly tuberculate and spiny as in male. Oviger without reversed spines on segments 4, 5, and 6; segment 7 longer than in male; segment
10 with 1 compound and 1 simple spine. Distal palp segments: see Fig. $4 \mathrm{e}$.

Measurements of male from sta. 91-79 (mm). Length trunk (frontal margin cephalon to tip of 4th lateral process) 0.87 ; diameter of trunk across 2 nd 


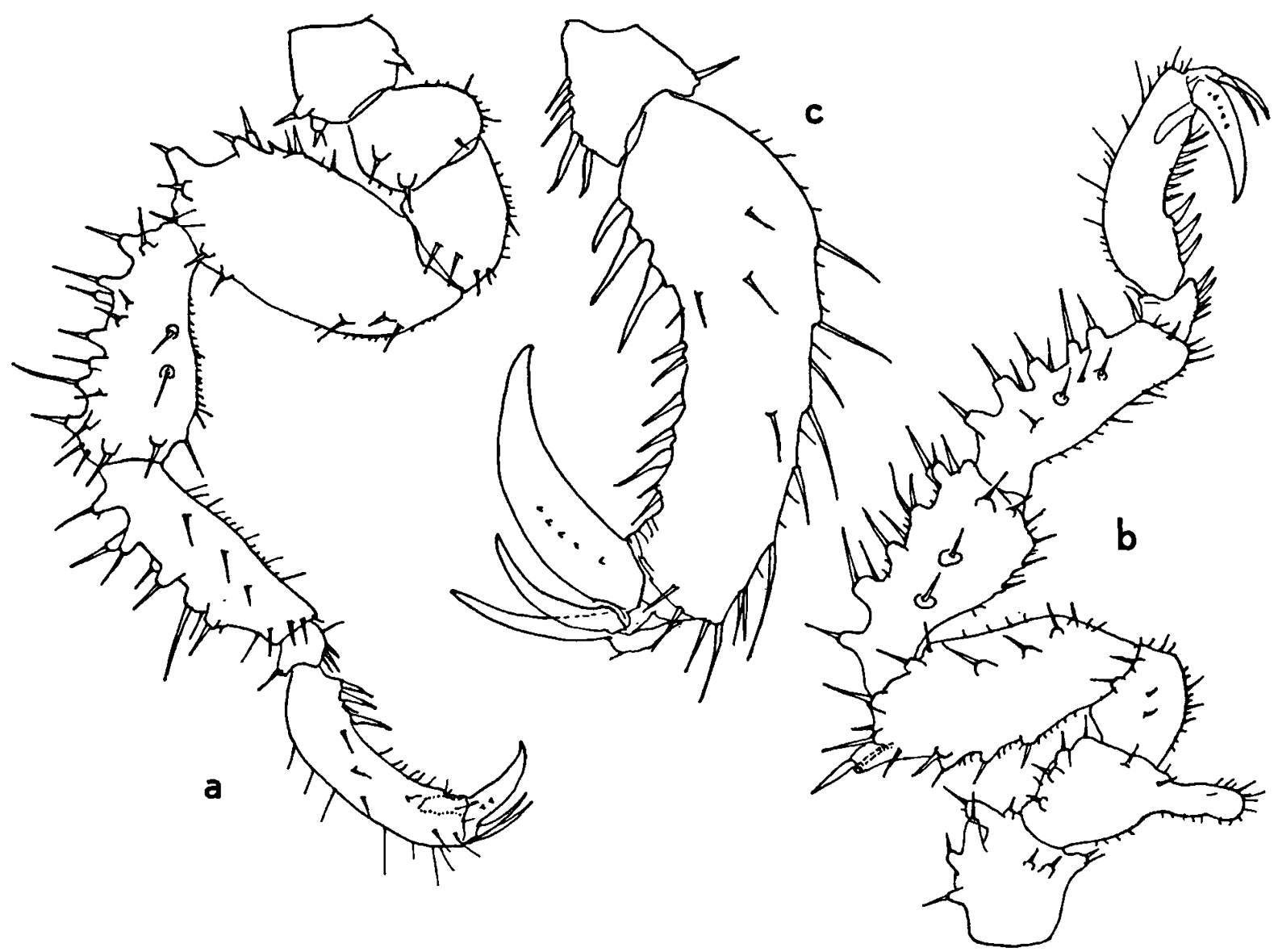

Fig. 5. Achelia boschi n. sp., from sta. 91/79: a, leg 3, ९; b, leg 3, o; c, distal segments of leg 3, $\sigma^{\circ}$

lateral processes 0.83 ; length proboscis (dorsal) 0.52 ; greatest diameter proboscis 0.29 ; length abdomen 0.25 .

Third leg: first coxa 0.24 ; second coxa 0.27 ; third coxa 0.15 ; femur 0.49 ; first tibia 0.43 ; second tibia 0.45 ; tarsus 0.08 ; propodus 0.38 ; claw 0.22 ; auxiliary claws 0.13 .

Etymology. - Named in honour of D.T. Bosch, M.D., a well-known malacologist, who has studied during 27 years the marine fauna of the Arabian Gulf, and who has supported the recent Amsterdam expedition to Oman in various ways.

Remarks. - The new species, Achelia boschi, belongs to a group of taxa closely-knit around $A$ chelia echinata Hodge, 1864, comprising besides $A$. echinata and its various subspecies and varieties, $A$. nana (Loman, 1908), A. vulgaris (Costa, 1861), and $A$. brevicauda (Loman, 1904).

All these species differ from $A$. boschi in having more slender legs (in both sexes), and a weaker tuberculation of the long leg segments (in male, but in particular in female). In $A$. boschi the distal palp segments are short and bulgy, in all others (except for $A$. brevicauda) segments 6 and 8 are more elongate, and none of the segments is bulgy. In $A$. boschi the femur is the longest leg segment, in all other species of the group tibia 2 is longer than tibia 1 , which is again longer than the femur (cf. Figs. 5 and 6).

Through the more or less similar structure of the palp and the short abdomen, $A$. boschi shows the greatest resemblance to $A$. brevicauda from South Africa. I checked Loman's male holotype and some other specimens in the collection of the Zoölogisch 


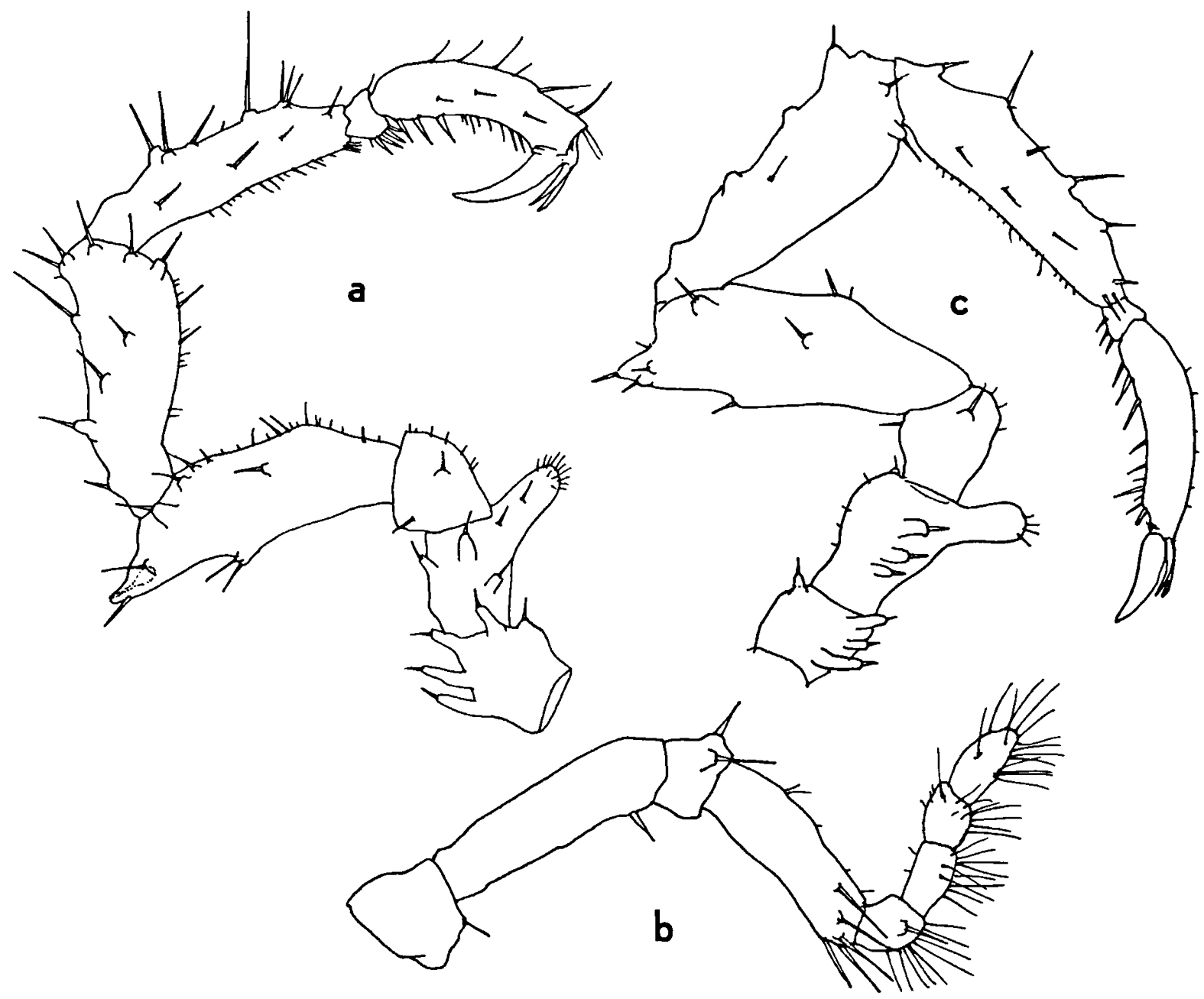

Fig. 6. Look-alikes of Achelia boschi: a-b, Achelia echinata Hodge, 1864, from Roscoff, o (leg 3 and palp); c, Achelia nana (Loman, 1908), from Siboga Exped. sta. 172, ơ (leg 3).

Museum, Amsterdam, and noticed the following additional differences between $A$. brevicauda and $A$. boschi : the chelifores are one-third of the dorsal length of the proboscis in $A$. brevicauda, almost half that length in $A$. boschi; the female of $A$. brevicauda lacks strong tubercles on the femur and on tibiae 1 and 2; and the frontal margin of the cephalic segment is straight with angular corners in $A$. brevicauda, curved with rounded corners in $A$. boschi.

In order to appreciate some of the differences, certain appendages of Achelia echinata (from the Roscoff area) and $A$. nana (one of Loman's syntypes, from Siboga Exped. sta. 172) have been re- illustrated here (Fig. 6). The palp of $A$. nana (not re-illustrated) does not differ significantly from that of A. echinata.

Achelia lagenaria n. sp.

(Figs. 7-8)

Material. - Sta. 91/79, $1 \sigma^{\circ}$ (holotype), $5 \sigma^{\circ}, 8$, 8,2 juvs. (paratypes) (ZMA Pa. 3568).

Description of male. - Trunk (Fig. 7a) with 1 segmentation line only, ovate in outline; lateral processes touching, each process distally armed 

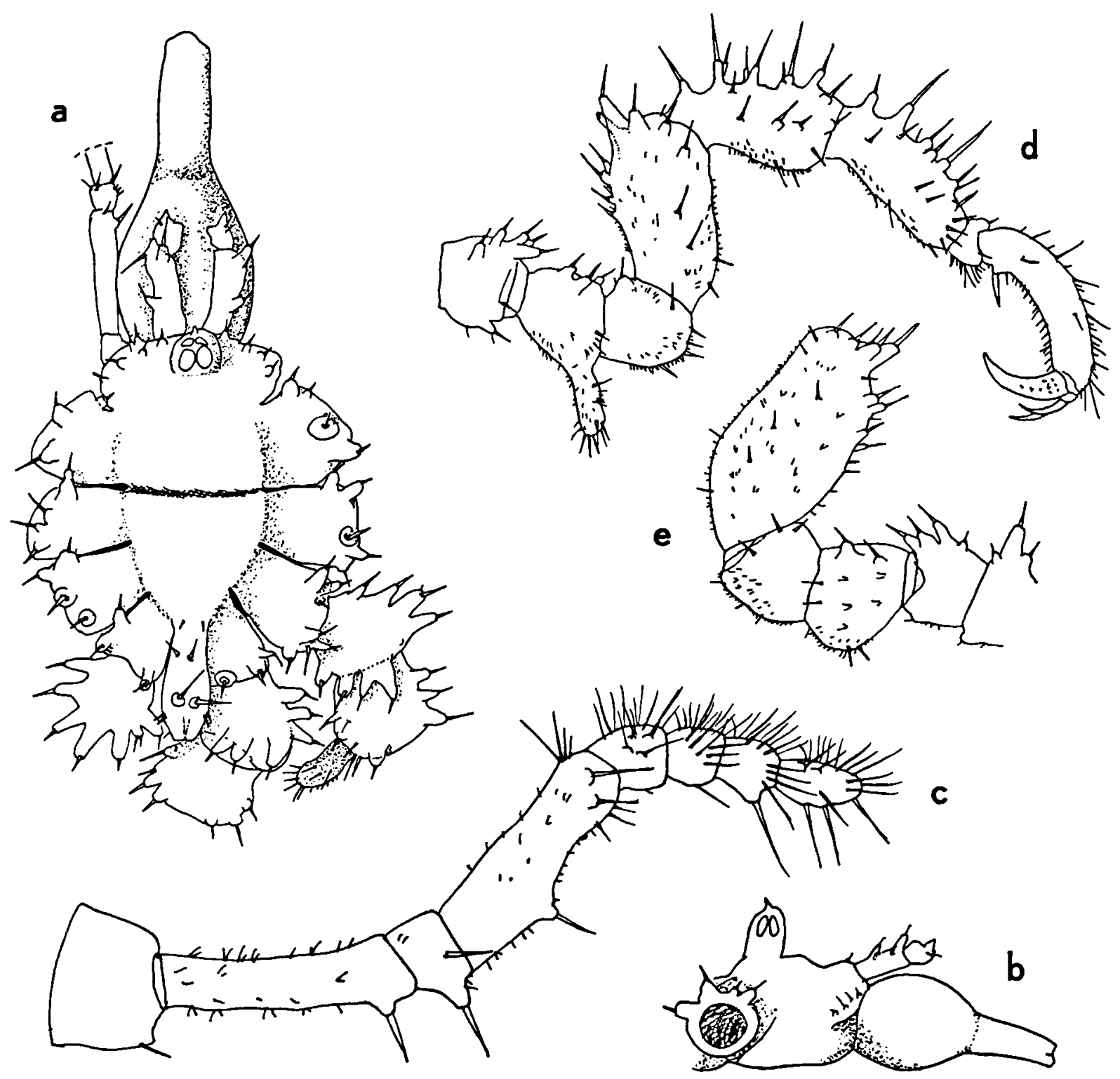

rig. 7. Achelia lagenaria $n$. sp., from sta. 91/79: a, trunk, $\sigma^{\circ}$, dorsal; b, cephalic segment, $\&$, from the right; c, palp, $\sigma^{\circ}$;, leg 3, ó; e, lateral process, coxae, and femur of leg $3, Q$. [a, d, and e to same scale.]

with 3 to 6 spine-tipped tubercles or prominences. Abdomen overreaching 4th lateral process, dorsally with several spinules and 2 low spine-tipped tubercles. Frontal margin of cephalic segment with small spiniferous tubercles. Ocular tubercle cylindrical, apex produced into small point; eyes pigmented. Proboscis straight, slightly directed ventrad (at an angle of $20-30^{\circ}$ ); shaped as a bottle, with bulbous basal half and long distal neck.

Chelifore (Fig. 8b) scape 1-segmented, with 2 spiniferous spurs; chela globular, with 1 triangular process and 1 or 2 strong spines.

Palp (Fig. 7c) 8-segmented; strong spines on segments 2, 3, and 4; distal 4 segments densely setose; segments 5,6 , and 7 as long as wide, segment 8 ovate. 


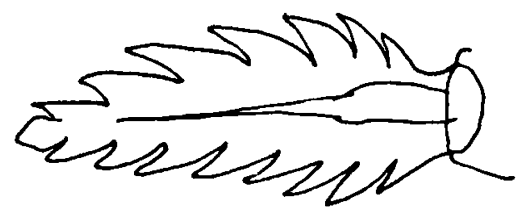

a
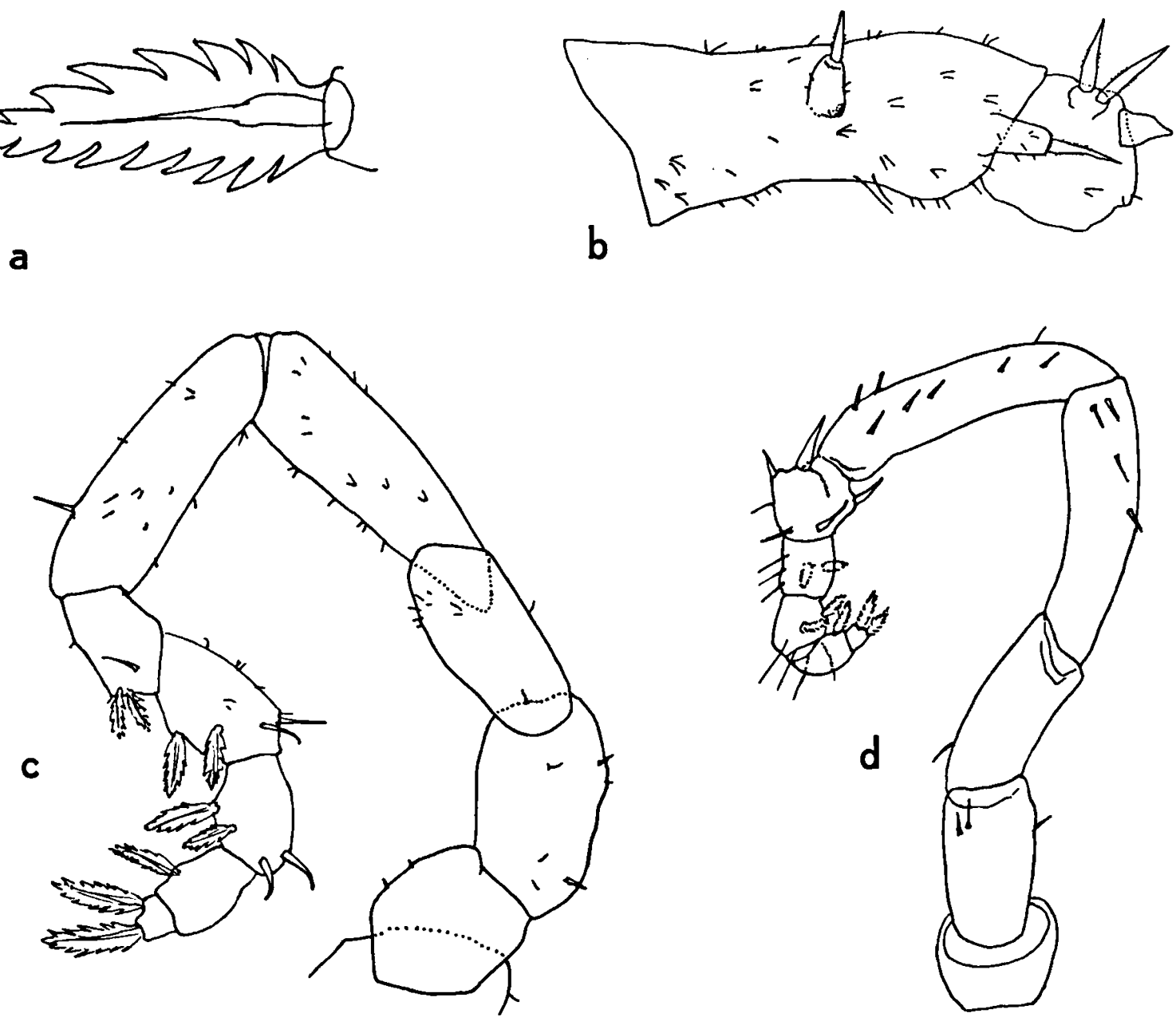

Fig. 8. Achelia lagenaria n. sp., from sta. 91/79: a, compound spine of oviger segment 10, $\sigma^{\circ}$; b, chelifore, $\sigma^{\circ}$; c, oviger, ९; d, oviger, $\sigma^{\circ}$.

Oviger (Fig. 8d) 10-segmented; segments 4 and 5 with reversed spinules; segment 6 with 4 stronger reversed spines. Compound spine formula $2: 2: 1: 2$; compound spines of distal segments (Fig. 8a) with more (up to 7) marginal teeth than those of proximal segments (4 teeth).

Legs (Fig. 7d): Coxa 1 with 3 or 4 spiniferous spurs on anterior and posterior margins. Coxa 2 with 2 or 3 lower spurs on each margin. Coxa 2 of legs 3 and 4 with long, finger-shaped genital process. Femur and tibiae 1 and 2 with numerous processes, partly tall, partly low, each armed with a spine. Propodus curved; heel well-indicated, armed with single long spine (exceptionally, this spine is lacking, or it is accompanied by a smaller spine); sole with numerous small spinules. Claw curved, basal part with several minute denticles. Auxiliary claws about half as long as claw.

Female. - Genital pore on ventral surface of coxa 2 of all legs. Legs (Fig. 7e): femur swollen. Armature of trunk and legs slightly, but not much, less pronounced than in male. Oviger (Fig. 8c) segments 4,5 , and 6 without reversed spines. Cephalic segment illustrated (Fig. 7b).

Measurements of male (mm). - Length trunk (frontal margin cephalon to tip 4th lateral process) 1.15; width across 2 nd lateral processes 1.01 ; length proboscis (ventral) 1.23; greatest diameter 


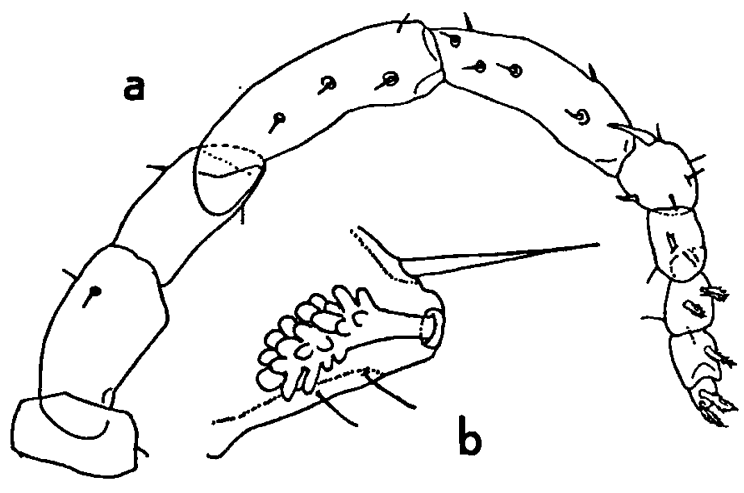

Fig. 9. Achelia watamu (Müller, 1990), from sta. 91/117: a, oviger, $\sigma^{\prime} ; b$, cement gland of third leg, $\sigma^{\circ}$.

proboscis 0.52 ; distal diameter proboscis 0.15 ; length abdomen 0.35 ; length scape 0.30 .

Third leg: First coxa 0.23; second coxa 0.32; third coxa 0.19 ; femur 0.53 ; first tibia 0.47 ; second tibia 0.51 ; tarsus 0.11 ; propodus 0.53 ; claw 0.27 ; auxiliary claws 0.14 .

Remarks. - Achelia lagenaria is characterized by two features which are both unusual in the genus: (1) the proboscis shape (straight, basal part swollen, distal part tubiform), and (2) the presence of 1 large propodal heel spine only. In combination, these two easily observable characters serve to separate $A$. lagenaria from all other species in the genus, including $A$. boschi, with which it co-occurs in the same sample.

Etymology. - A lagena (Latin) is a bulgy bottle with a long neck; the derivation lagenaria (bottleshaped) alludes to the shape of the proboscis.

\section{Achelia watamu (Müller, 1990)}

(Fig. 9)

Ammothea watamu Müller, 1990a: 63-66, figs. 1-6.

Material. - Sta. 91/79, 1 \&; sta. 91/117, 1 o ovig., $3 \sigma^{\circ} \circ, 3$ Q $\%$.

Remarks. - The Oman specimens agree very well with Müller's description based on littoral material from Kenya. The chelifore stumps, palps and legs carry slightly more spines and setae, but this is con- sidered of no taxonomic importance. On the other hand, the male oviger is re-illustrated here (Fig. 9a), because Müller's drawing does not show the small reversed spines on segment 5 and the large reversed spine on segment 6 .

Fig. $9 \mathrm{~b}$ shows the unusual cement gland: normally, this gland is a rounded or ovate vesicle, but in A. watamu it is shaped like a bunch of grapes.

Although I admit that the general habitus of this species is very much like Ammothea (Lecythorhynchus), and that it is not surprising that Müller attributed his species to this genus, I think, after close examination, that it actually belongs to Achelia, since it has 8-segmented palps (9-segmented in $\mathrm{Am}$ mothea), it lacks raised posterior rims on the trunk segments (more or less pronounced in Ammothea), it possesses a strong male genital spur (no spur in Ammothea), it has a tuberculate coxa 1 , which is more like Achelia than like Ammothea, the male femur carries a terminal cement gland aperture (subterminal in Ammothea), oviger segments 7 and 8 are synaxially articulated (anaxially in $\mathrm{Am}$ mothea), whereas male oviger segment 6 is shortish and armed with a reversed spine (elongate, without reversed spine, in Ammothea).

A. watamu is one of the few species of Achelia having a single-segmented chelifore (chela completely lacking). A. transfuga Stock, 1954 from New Zealand has a similar chelifore, but it differs strongly from $A$. watamu by its curved, distally tubiform, proboscis and the absence of auxiliary claws. Fry \& Hedgpeth (1969) considered these characters of $A$. transfuga of sufficient importance to base a new genus upon, called Aduncorostris. However, an Australian species, $A$. transfugoides Stock, 1973 , resembling $A$. transfuga in many features, has certain characters (notably the presence of small auxiliary claws) that tend to invalidate the generic status of Aduncorostris.

\section{Tanystylum bredini Child, 1970}

Tanystylum bredini Child, 1970: 296-299; Child, 1977: 441; Müller, 1989: 125, figs. 11-21; Müller, 1990a: 67, figs. 7-15.

Material. - Sta. 91/79, $1 \sigma, 2$ ९ \&; sta. 91/94, $1 \sigma, 1$ \%; sta. $91 / 105,1$ \% 

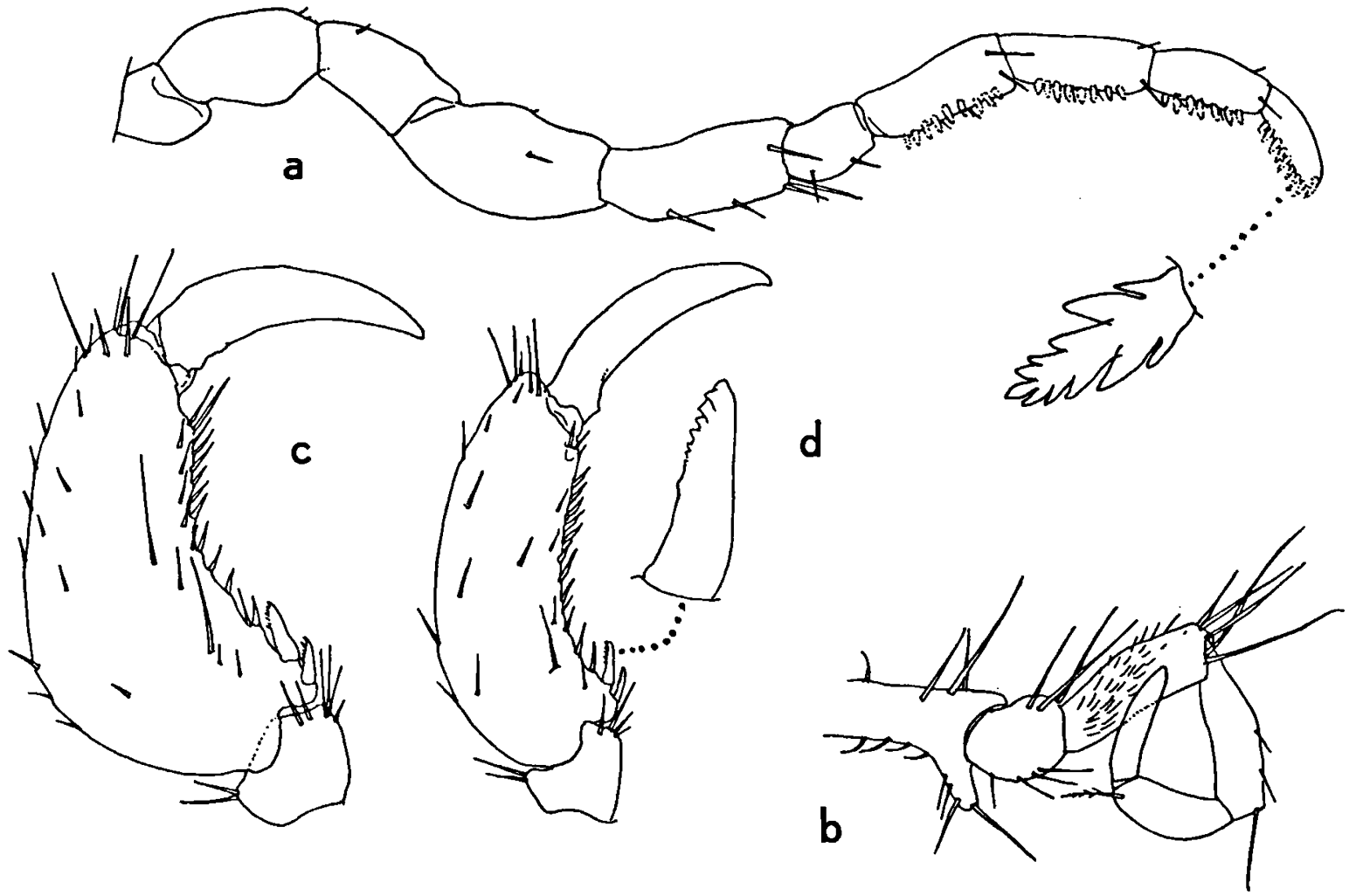

Fig. 10. Propallene crassimanus Stock, 1959, from sta. 91/58: a, oviger, $९$; b, distal part of oviger, ơ; c, distal segments of leg 3, o ; d, distal segments of leg 3 , $\%$.

Remarks. - These specimens resemble the typeseries (from the Society Islands in the Pacific) quite well. Müller (1989, 1990a) has stressed the variability in some characters. The oviger of the Oman female is 9-segmented, just as recorded by Child (1970) and Müller (1990a). However, Müller (1989) describes and illustrates a female with 8-segmented ovigers.

The species was already known from the Society Islands, Tuamotu Archipelago (French Oceania), Sri Lanka, and Kenya.

\section{Pigrogromitus timsanus Calman, 1927}

Pigrogromitus timsanus; Stock, 1991: 194 (refs.).

Material. - Sta. 91/50, 1 o ovig.; sta. 91/83, 1 specimen; sta. 91/117, 7 specimens.

Remarks. - P. timsanus is a pan-tropical shallow- water species, although it is most frequently recorded from the Indo-West Pacific. Outside this area it has been observed on the Mediterranean coast of Israel (Stock, 1968: 46), in the West Indies (Stock, 1989: 95), Belize (Child, 1982a: 367), and on the Pacific coast of Panamá (Reimer, 1976), but it is not excluded that it has been introduced through shipping activities in these localities. There are two dubious records from the deep sea (New Caledonia, 2040-2050 m; Stock, 1991).

This species was already known from the Gulf of Oman (Stock, 1968: 46), although from deeper waters $(108 \mathrm{~m})$.

Propallene crassimanus Stock, 1959

(Fig. 10)

Propallene crassimanus Stock, 1959: 559-561, fig. 5; Stock, 1975b: 94 (in key). 
Material. - Sta. 91/58, 11 ơ o; 3 ९ ९; sta. 91/74, 1 \&, 1 juv.; sta. 91/79, 10 ơ $\sigma, 7$ ㅇ, 5 juvs.; sta. 91/105, 1 ९.

Remarks. - Propallene crassimanus was known from a single male specimen, collected in $17 \mathrm{~m}$ off Lambert's Bay, South Africa. The present specimens are in good agreement with the holotype, except for a lower number of femoral cement gland tubes. In the holotype there are 14 tubes per femur, in the present material 8 to 10 tubes.

The female is recorded here for the first time. As in some other species of the genus Propallene (e.g., P. curtipalpus Child, 1988, P. cyathus Staples, 1979, P. vaga Staples, 1979), there exists a marked sexual dimorphism in the propodus of $\boldsymbol{P}$. crassimanus as well (wider in male, narrower in female, cf. Figs. 10c, d).

The distal segments of the male oviger, lacking in the holotype, are illustrated here (Fig. 10b), as well as the sexually dimorphic female oviger (Fig. 10a).

\section{Callipallene gabriellae Corrêa, 1948}

Callipallene gabriellae Corrêa, 1948: 1-4, figs. 1-6; Stock, 1992: 128.

Callipallene kenyensis Müller, 1990a: 71-74, figs. 21-26 [new synonymy].

Material. - Sta. 91/65, $1 \circ^{\circ, 1} 1$ \&, 1 juv.; sta. 91/74, 3 o $\sigma^{\circ}$ ovig., 1 \% , 3 \&, 14 juvs. and larvae; sta. 91/79, 1 \&, 2 juvs.; sta. 91/93, $1 \sigma$; sta. 91/94, $1 \sigma$ ovig., $1 \sigma$; sta 91/99, $1 \sigma^{\circ}$, 1 \&; sta. 91/105, 1 \%.

Remarks. - The specimens from sta. 91/94 are carmine-red in preserved state. The morphology of the Oman material corresponds exactly with Corrêa's description. As remarked elsewhere (Stock, 1992), this species is extremely close to C. emaciata (Dohrn, 1881), but it possesses fewer teeth on the fingers of the chela. In the Oman material, the fingers carry 8 teeth (in C. emaciata there are, according to Child, 1979: 41, in key, about 15 teeth).

The presence of $C$. gabriellae on the Oman coast poses a biogeographical enigma: previous records were all from southern Brazil, but if we accept the synonymy with $C$. kenyensis Müller, 1990, the nearest record is on the Kenya coast.

\section{Anoplodactylus angulatus (Dohrn, 1881)}

Principal refs.: Phoxichilidium angulatum Dohrn, 1881: 184-188, pl. XII figs. 1-12.

Phoxichilidium angulirostre [lapsus calami] Dohrn, 1881: 34, 35, 68.

Anoplodactylus angulatus; Bouvier, 1923: 120; Lebour, 1945: 155-157, fig. 5; Krapp, 1973: 72, fig. 6.

Material. - Sta. 91/79, 1 o ovig., $1 \sigma^{\circ}, 1$ \%; sta. 91/61, 1 \%; sta. 91/99, 1 ९.

Remarks. - This is a common and often recorded littoral and shallow-water species in the NorthWest Atlantic, from Northern Ireland (Roberts, 1981) to the Canary Islands (Sánchez \& Munilla, 1989; Stock, 1990) and in the entire Mediterranean (Arnaud, 1988). The species was never found in the Indian Ocean, but the Oman specimens fit completely the differential diagnoses provided by Lebour (1945, based on specimens from Plymouth) and Krapp (1973, based on specimens from Sicily).

The identification of the isolated females in samples $91 / 61$ and $91 / 99$ is under reservation, since female specimens unaccompanied by males are hard to identify in this large genus.

\section{Anoplodactylus digitatus (Böhm, 1879)}

Anoplodactylus digitatus; Stock, 1965: 28-29 (earlier lit. \& syn.); Stock, 1968: 49; Lipkin \& Safriel, 1971: 9, 23, 24; Arnaud, 1988: 45.

Anoplodactylus spec. B, Clark, 1963: 55, fig. 28.

Material. - Sta. 91/50, $1 \sigma^{\circ}$.

Remarks. - This species is widely distributed in shallow tropical and subtropical waters, almost worldwide.

\section{Anoplodactylus glandulifer Stock, 1954}

Anoplodactylus glandulifer Stock, 1954: 80-84, fig. 36; Stock, 1958: 3; Stock, 1968: 49; Arnaud, 1973; 955, figs. 1-2; Stock, 1974: 16-17; Child, 1982a: 273-274; Nakamura \& Child, 1988: 
813; Child, 1988b: 59; Müller, 1990a: 74; Child, 1990: 331; Child, 1991: 143-144.

Anoplodactylus sp., Calman, 1923: 289.

Material. - Sta. 91/83, 1 ○ ovig., $5 \circ \circ, 4$ \% $\%$; sta. 91/99,

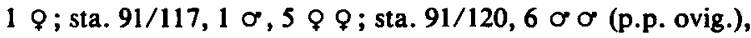
6 ㅇ, 1 juv.

Remarks. - This species is widespread in the IndoWest Pacific. It has been recorded from Enewetak, Samoa, Guam, the Great Barrier Reef, Singapore, Birma, Madagascar, Aldabra, Kenya, and Eilat. Most of these records are from the intertidal zone or very shallow waters. Most of the present specimens are, in preserved state, bright blue-green in colour.

\section{Anoplodactylus tarsalis Stock, 1968}

Anoplodactylus tarsalis Stock, 1968: 52-53, fig. 19; Arnaud, 1973: 955; Stock, 1986: 700; Child, 1988a: 20; Child, 1988c: 424; Müller, 1990a: 78.

Material. - Sta. 91/79, 3 ९ ९.

Remarks. - This psammophilous species is apparently widely distributed in the Indo-West Pacific. It has been recorded from several places in the Philippines, Madagascar, and Kenya. The present record extends the range to the Arabian peninsula. Morphologically, $A$. tarsalis is very close to $A$. evelinae Marcus, 1940, from the warm-water region of the Atlantic, but it can be distinguished by a wider neck, bearing 2 well-developed knobs (probably palp rudiments), and by somewhat more elongate second tibiae.

The number of wedge-shaped spines on the propodal sole varies from 5 to 6 in the present material (4 in the holotype from the Philippines).

The mid-dorsal line of trunk segments 2 and 3 in the Oman specimens is somewhat swollen, in one specimen assuming the shape of tubercles. Middorsal tubercles are also present in $A$. evelinae, however, on trunk segments 1 and 2.
Pycnogonum (s.1.) moolenbeeki n. sp. (Fig. 11)

Material. - Sta. 91/111, 1 \% (holotype), 1 \% (paratype) (ZMA Pa. 3543).

Description. - Female. Small-sized, non-reticulate species. Trunk segments 1, 2, and 3 articulated, segments 3 and 4 partially fused (Figs. 11a, d). Abdomen with distinct basal articulation, sausageshaped, reaching to distal end of coxa 2 of leg 4 . Mid-dorsal line of trunk segments 1, 2, and 3 slightly raised, without forming real dorsal tubercles. One minute tubercle on distal end of each lateral process. Distinct interval between lateral processes 1 and 2, and 2 and 3; lateral processes 3 and 4 almost touching. Ocular tubercle low, truncate cone; eyes present.

Proboscis of type $B^{\prime}: 1$ (sensu Fry \& Hedgpeth, 1969); tip rounded; much longer than abdomen. At about $2 / 3$ of its length, mid-dorsal line of proboscis produced into triangular projection.

Legs (Figs. 11b, c): Coxae 1 and 2 with rounded bosses; coxa 3 not tuberculate; femur with 2 strong dorsal bosses in basal half, 2 strong distal lobes, and 1 low dorsal boss in distal half bearing 1 long spine. Tibia 1 about twice as long as wide, with 2 dorsal tubercles and 2 distal tubercles, and 1 long spine. Tibia $2<$ tibia 1 , with 2 dorsal and 2 distal tubercles, and 1 long spine; distoventral end of tibia 2 and ventral margins of tarsus and propodus densely set with spinules, which are molariform at tip. Claw curved, no auxiliary claws. Female genital aperture on dorsal surface of coxa 2 of all legs.

Measurements, female (mm). - Length trunk (frontal margin cephalon to tip 4th lateral process) 1.81 ; width across 2 nd lateral processes 1.07 ; length proboscis (dorsal) 0.81 ; greatest diameter proboscis 0.39 ; length abdomen 0.48 .

Leg 1: First coxa 0.26; second coxa 0.28; third coxa 0.25 ; femur 0.66 ; first tibia 0.34 ; second tibia 0.25 ; tarsus 0.12 ; propodus 0.38 ; claw 0.17 .

Etymology. - Named in recognition of the efforts made by the collector of the Oman material, Robert G. Moolenbeek. 

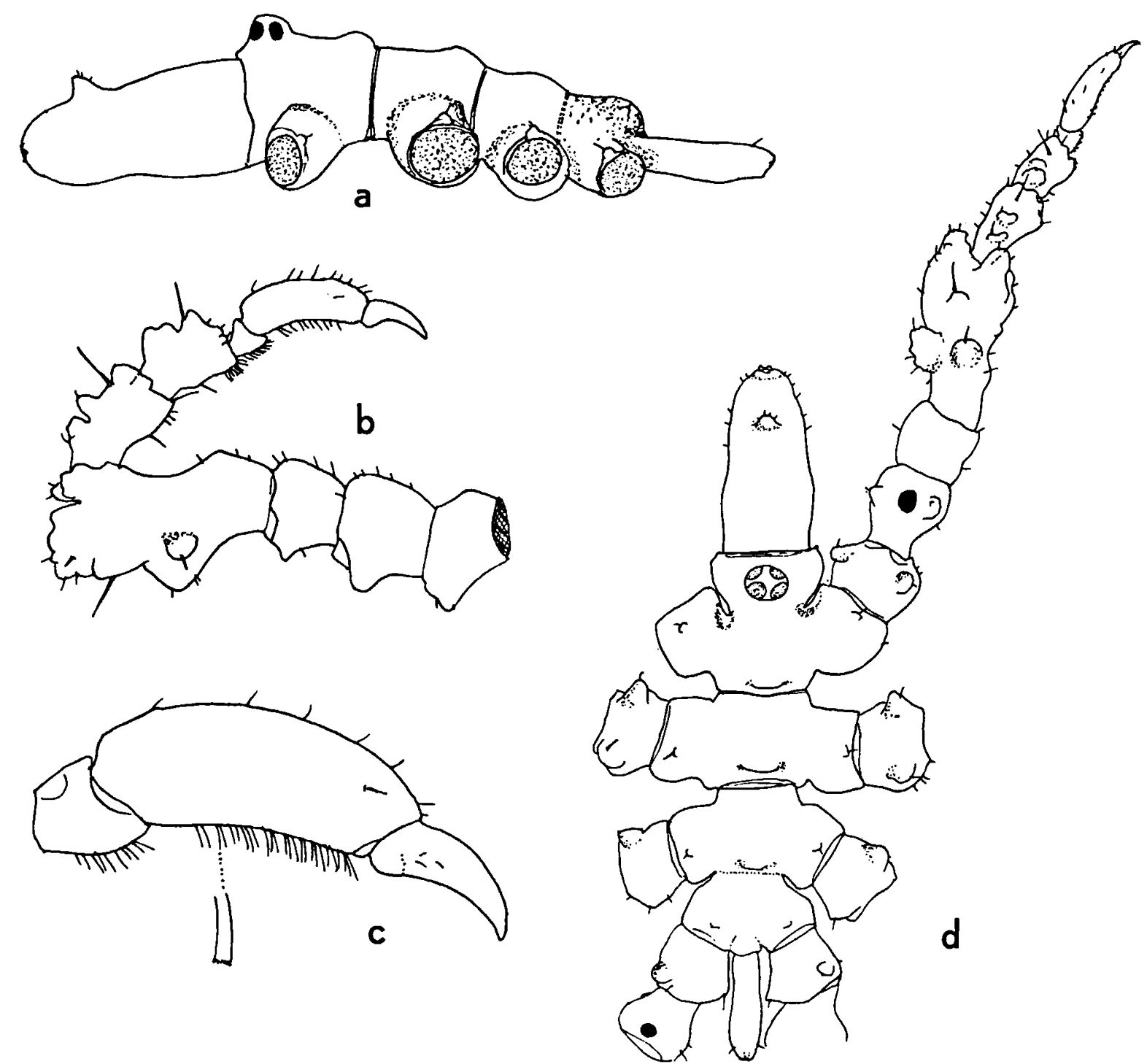

Fig. 11. Pycnogonum moolenbeeki n. sp., females from sta. 91/111: a, trunk, paratype, from the left; b, leg 2, paratype; c, distal segments of leg 2, paratype; d, holotype, dorsal. [Black dot on dorsal surface of coxa 2 in Fig. 11d denotes the female genital orifice.]

Remarks. - By the presence of a single, mid-dorsal prominence on the proboscis, and the basal articulation of the abdomen, Pycnogonum moolenbeeki is phenetically very close to the Mediterranean $P$. nodulosum Dohrn, 1881 ( = P. rhinoceros Dohrn, 1881: 38, 66) and $P$. tuberculatum Clark, 1963, from S.E. Australia.

It differs from $P$. nodulosum in the $\$$ genital apertures (on dorsal surface of coxa in $P$. moolenbeeki, on ventral surface in $P$. nodulosum); the more widely spaced lateral trunk processes of $\boldsymbol{P}$. moolenbeekl; the much stronger tubercles on the lateral trunk processes of $P$. nodulosum; the partially fused trunk segments 3 and 4 of $P$. moolenbeeki; the different tuberculation pattern of the femur; the propodus, which is narrower and more slender in $P$. nodulosum; tibia 1 , which is about 3 times as long as wide in $P$. nodulosum, only twice in $P$. moolenbeeki.

Differences between $P$. moolenbeeki and $P$. tuberculatum pertain to the shape and length of the proboscis (short, cylindrical to barrel-shaped in 
$P$. tuberculatum; long, more spindle-shaped in $P$. moolenbeeki); the shorter tibia 1 of $P$. moolenbeeki; the stronger development of tubercles on coxae 1 and 2 , and tibiae 1 and 2 , of $P$. moolenbeeki; the less robust propodus of $P$. tuberculatum; and the smaller size of $P$. moolenbeeki.

In none of these three species is the male known, making a subgeneric allocation of these species impossible at the moment.

\section{Acknowledgement}

I am indebted to Mr. Robert G. Moolenbeek (Department of Malacology, Institute of Taxonomic Zoology, University of Amsterdam) for entrusting me with this interesting collection for examination.

\section{References}

Arnaud, F., 1973. Pycnogonides des récifs coralliens de Madagascar, 4. Colossendeidae. Phoxichilidiidae et Endeidae. Téthys, 4(4) (“1972"): 953-960.

Arnaud, F., 1988. Les Pycnogonides (Chelicerata) de Méditerranée: distribution écologique, bathymétrique et biogéographie. Mésogée, 47 (“1987”): 37-58.

Bouvier, E.L., 1923. Quelques notes sur les Pycnogonides des côtes de France. Annls. Sci. nat. Zool., (10) 6: 117-124.

Calman, W.T., 1923. Pycnogonida of the Indian Museum. Rec. Indian Mus., 25 (3): 265-299.

Child, C.A. 1970. Pycnogonida of the Smithsonian-Bredin Pacific Expedition, 1957. Proc. biol. Soc. Wash., 83 (27): 287-308.

Child, C.A., 1975. Pycnogonida of Western Australia. Smithson. Contr. Zool., 190: i-iv, 1-29.

Child, C.A., 1977. On some Pycnogonida of French Oceania. Proc. biol. Soc. Wash., 90 (2): 440-446.

Child, C.A., 1979. Shallow-water Pycnogonida of the Isthmus of Panama and the coasts of Middle America. Smithson. Contr. Zool., 293: i-iv, 1-86.

Child, C.A., 1982a. Pycnogonida of the western Pacific islands, 1. The Marshall Islands. Proc. biol. Soc. Wash., 95 (2): 270-281.

Child, C.A., 1982b. Pyenogonida from Carrie Bow Cay, Belize. Smithson. Contr. mar. Sci., 12: 355-380.

Child, C.A., 1988a. Pycnogonida of the western Pacific islands, III. Recent Smithsonian-Philippine expeditions. Smithson. Contr. Zool., 468: i-iv, 1-32.

Child, C.A., 1988b. Pycnogonida from Aldabra atoll. Bull. biol. Soc. Wash., 8: 45-78.

Child, C.A., 1988c. Pycnogonida Chapter 45 in: R.P. Higgins $\&$ H. Thiel (eds.), Introduction to the study of meiofauna:
423-424 (Smithsonian Institution Press, Washington/ London).

Child, C.A., 1990. Pycnogonida of the western Pacific islands, VIII. Recent collections from islands of the Great Barrier Reef, Australia. Proc. biol. Soc. Wash., 103 (2): 311-335.

Child, C.A., 1991. Pycnogonida of the western Pacific islands, IX. A shallow-water Guam survey. Proc. biol. Soc. Wash., 104 (1): 138-146.

Child, C.A., 1992. Shallow-water Pycnogonida of the Gulf of Mexico. Mem. Hourglass Cruises, 9 (1): 1-86.

Clark, W.C., 1963. Australian Pycnogonida. Rec. Aust. Mus., 26 (1): 1-81.

Corrêa, D.D., 1948. Callipallene gabriellae, novo Pantópodo de Santos. Papéis avuls. Dep. Zool. S. Paulo, 9(1): 1-12.

Dohrn, A., 1881. Die Pantopoden des Golfes von Neapel und der angrenzenden Meeres-Abschnitte. Fauna Flora Golf. Neapel, Monogr. 3: 1-252, Pls. I-XVIII.

Fry, W.G. \& J.W. Hedgpeth, 1969. The fauna of the Ross Sea, 7: Pycnogonida, 1. Colossendeidae, Pycnogonidae, Endeidae, Ammotheidae. New Zealand oceanogr. Inst. Mem., 49 (= Bull. New Zealand Dep. scient. ind. Res., 198): 1-139.

ICZN, 1985. International Code of Zoological Nomenclature, ed. 3: i-xx, 1-338 (University of California Press, Berkeley \& Los Angeles).

Krapp, F., 1973. Pycnogonida from Pantelleria and Catania, Sicily. Beaufortia, 21 (277): 55-74.

Kurian, C.V., 1953. A preliminary survey of the bottom fauna and bottom deposits of the Travancore coast within the 15-fathom zone. Proc. natn. Inst. Sci. India, 19 (6): 746-775, 1 chart.

Lebour, M.V., 1945. Notes on the Pycnogonida of Plymouth. J. mar. biol. Ass. U.K., 26: 139-165.

Lipkin, Y. \& U. Safriel, 1971. Intertidal zonation on rocky shores at Mikhmoret (Mediterranean, Israel). J. Ecol., 59 (1): 1-30.

Marcus, E. du Bois-Reymond, 1952. A hermaphrodite pantopod. Anais Acad. bras. Ciênc., 24 (1): 23-30.

Müller, H.-G., 1989. Shallow-water Pycnogonida from coral reefs at Moorea, Society Islands, with description of Rhynchothorax tiahurensis n. sp. Bonn. zool. Beitr., 40 (2): 123-139.

Müller, H.-G., 1990a. Shallow-water Pycnogonida from Kenya and Sri Lanka, with descriptions of three new species. Bonn. zool. Beitr., 41 (1): 63-79.

Müller, H.-G., 1990b. On some Indo-West-Pacific Pycnogonida from the Zoologisk Museum, Copenhagen. Zool. Abh. staatl. Mus. Tierk. Dresden, 45 (10): 103-110.

Nakamura, K. \& C.A. Child, 1988. Pycnogonida of the western Pacific islands. V. A collection by the Kakuyo Maru from Samoa. Proc. biol. Soc. Wash., 101 (4): 809-816.

Reimer, A.A., 1976. Description of a Tetraclita stalactifera panamensis community on a rocky intertidal Pacific shore of Panama. Mar. Biol., 35 (3): 225-238.

Roberts, D., 1981. Pycnogonids from Strangford Lough, Northern Ireland. Ir. Natural J., 20 (5): 189-192.

Sánchez, E. \& T. Munilla, 1989. Estudio ecológico de los 
primeros Picnogonidos litorales de las islas Canarias. Cah. Biol. mar., 30: 49-67.

Stock, J.H., 1953. Biological results of the Snellius Expedition, 17. Contribution to the knowledge of the pycnogonid fauna of the East Indian archipelago. Temminckia, 9: 276-313.

Stock, J.H., 1954. Pycnogonida from Indo-West-Pacific, Australian, and New-Zealand waters. Vidensk. Meddr. dansk naturh. Foren., 116: 1-168.

Stock, J.H., 1957. Pycnogonida from the Gulf of Aqaba. Bull. Sea Fish. Res. Stn. Haifa, 13: 13-14.

Stock, J.H., 1958. The Pycnogonida of the Erythrean and of the Mediterranean coasts of Israel. Bull. Sea Fish. Res. Stn. Haifa, 16: 3-5.

Stock, J.H., 1959. On some South African Pycnogonida of the University of Cape Town Ecological Survey. Trans. roy. Soc. S. Afr., 35 (5): 549-567.

Stock, J.H., 1964. Report on the Pycnogonida of the Israel South Red Sea Expedition. Bull. Sea Fish. Res. Stn. Haifa, 35: 27-34.

Stock, J.H., 1965. Pycnogonida from the southwestern Indian Ocean. Beaufortia, 13 (151): 13-33.

Stock, J.H., 1968. Pycnogonida collected by the Galathea and Anton Bruun in the Indian and Pacific Oceans. Vidensk. Meddr. dansk. naturh. Foren., 131: 7-65.

Stock, J.H., 1974. Medio- and infralittoral Pycnogonida collected during the I.I.O.E. near the landbase on Nossi-Bé, Madagascar. Bull. zoöl. Mus. Univ. Amsterdam, 4 (3): 11-22.

Stock, J.H., 1975a. Infralittoral Pycnogonida from Tanzania. Trav. Mus. Hist. nat. “Gr. Antipa”, 16: 127-134.

Stock, J.H., 1975b. The pycnogonid genus Propallene Schim- kewitsch, 1909. Bull. zoöl. Mus. Univ. Amsterdam, 4 (11): 89-97.

Stock, J.H., 1982. Researches on the coast of Somalia. Shallowwater Pycnogonida. Monitore zool. ital., (n.S.) 17 (Suppl. 7): 183-190.

Stock, J.H., 1986. Pycnogonida (= Pantopoda). In: L. Botosaneanu (ed.), Stygofauna mundi: 598-700 (E.J. Brill, Leiden).

Stock, J.H., 1989. Pycnogonida collected in interstitia of coral sand and rubble in the Netherlands Antilles. Bijdr. Dierk., 59 (2): 87-96.

Stock, J.H., 1990. Macaronesian Pycnogonida. Zoöl. Meded. Leiden, 63 (16): 205-233.

Stock, J.H., 1991. Deep-water Pycnogonida from the surroundings of New Caledonia. In: A. Crosnier (ed.), Résultats des Campagnes MUSORSTOM, 8. Mém. Mus. natn. Hist. nat., (A) 151: 125-212.

Stock, J.H., 1992. Pycnogonida from southern Brazil. Tijdschr. Ent., 135 (1): 113-139.

Weidner, H., 1959. Die entomologischen Sammlungen des Zoologischen Staatsinstituts und Zoologischen Museums Hamburg, I. Pararthropoda und Chelicerata, I. Mitt. hamburg. zool. Mus. Inst., 57: 89-142.

Williams, G., 1933. On Nymphopsis acinacispinatus, a new pycnogonid from Queensland. Ann. Mag. nat. Hist., (10) 12: 173-180.

Williams, G., 1940. Pycnogonida from Western Australia. J. roy. Soc. W. Aust., 25 (“'1938-39’”): 197-204.

Received: 4 June 1992. 